RESEARCH PAPER

\title{
"Not safe" is not enough: smokers have a right to know more than there is no safe tobacco product
}

\author{
L T Kozlowski, B Q Edwards
}

Tobacco Control 2005; 14(Suppl II):ii3-ii7. doi: 10.1136/tc.2004.008334

The right to health relevant information derives from the principles of autonomy and self direction and has been recognised in international declarations. Providing accurate health information is part of the basis for obtaining "informed consent" and is a recognised component of business ethics, safety communications, and case and product liability law. Remarkably, anti-tobacco and pro-tobacco sources alike have come to emphasise the message that there is "no safe cigarette" or "no safe tobacco product". We propose that the "no safe" message is so limited in its value that it represents a violation of the right to health relevant information. There is a need to go beyond saying, "there is no safe tobacco product" to indicate information on degree of risks. The "no safe tobacco" message does not contradict, for example, the mistaken belief that so called light or low tar cigarettes are safer choices than higher tar cigarettes. We encourage a kind of "rule utilitarian" ethical position in which the principle of truth telling is observed while trying to produce the greatest good for the greatest number of people.

Although harm reduction approaches to easing the burden of tobacco related diseases are founded on science based comparative risk information, the right to health information is independently related to the need to promote health literacy. This right should be respected whether or not harm reduction policies are judged advisable.

See end of article for authors' affiliations

Correspondence to: Professor Lynn TKozlowski, Department of Biobehavioral Health, Penn State, 315 East Health and Human Development, University Park, PA 16802, USA; ltk1@psu.edu
I ndividuals have a right to health relevant information; without it they cannot make meaningful health choices. Promoting and ensuring access to available knowledge is an obligation that follows from this right. Adequate ability to exercise the right of access to health relevant information has become a critical element of "health literacy". ${ }^{1-6}$ Tobacco control information campaigns have sometimes fallen short of meeting the obligation of health relevant information. Failure can take many forms. Not informing that a product or activity involves health risks is one obvious example. Providing wrong or incomprehensible information would be another. ${ }^{7}$ Saying too little can also be deceptive and a violation of rights.

In this paper, we review the foundation of the right to health relevant information and its close relationship to autonomy. We will consider whether one popular piece of health information about tobacco and cigarettes fails to meet the duty to inform. We focus on information on tobacco that, while not strictly untrue, provides so little important information that we think it represents a violation of the right to health relevant information. The popular message, often given as the central point of a communication, that "there is no safe cigarette" or "no safe tobacco product" is so uninformative that, on its own, it violates the right to health relevant information. Moreover, the very popularity of this message compounds the problem.

\section{THE BROAD BASES OF THE RIGHT TO HEALTH RELEVANT INFORMATION}

In earlier papers, we have described some of the diverse foundations of an individual right to honest, health relevant information. ${ }^{78}$ This right is supported by the Universal Declaration of Human Rights and is based on the principles of autonomy and self determination so highly valued in free societies. ${ }^{9}$ The principles of autonomy and self determination are also the basis of the doctrine of informed consent. Individuals cannot make autonomous, informed choices about their lives without pertinent and accurate information. Decisions made in ignorance or based on false information may only by accident reflect an individual's true preferences and do not permit real autonomy. ${ }^{11}{ }^{12}$

As the right to health relevant information is increasingly recognised, providing high quality information becomes critical. Women's health advocates, for example, have described the right to information as a necessary component of autonomy through self determination, citing international law in a call for national governments to provide the public with the information necessary to help make informed choices about reproductive health. ${ }^{13-15}$ Coliver asserts that, "the right to freedom of information increases with the importance of the information at issue to the individual or society". A right to be "properly informed" suggests that the very act of informing must be undertaken with care and consideration..$^{13} 14$

The right to accurate health information is also supported by the traditions of business ethics. The contract theory of a firm's duty to customers holds that both parties have voluntarily entered

Abbreviations: CDC, Centers for Disease Control and Prevention; FDA, Food and Drug Administration; FTC, Federal Trade Commission; NCl, National Cancer Institute; NIA, National Institute on Aging; PM, Philip Morris; SARS, severe acute respiratory syndrome 
into a contractual agreement (based upon sale and purchase). ${ }^{16}$ However, a contract can only be truly binding and voluntary when both parties have full knowledge of the agreement; further, "neither party to a contract must intentionally misrepresent the facts of the contractual situation to the other party" (page 340). This contract theory recognises that businesses have basic moral obligations to their customers, emphasises the need for parties to grasp the information presented to them, and requires that all the pertinent information be presented. (We would not suggest that the cigarette industry has been in compliance with these aspects of business ethics.)

Principles supporting the right to information are also evident in safety communication, where the purpose of warnings has been described as providing information about risks in such a way that allows people to make informed decisions. ${ }^{17}$ One principle is that when a reasonable duty to warn exists, the duty includes warning with force sufficient to convey the degree of danger involved. In addition to influencing behaviour in ways that encourage healthy decision making, there is another widespread purpose of warnings. Laughery \& Hammond describe meeting an individual's "right to know", about safety risks that might confront them. ${ }^{17}$ A great deal of case law also exists on product liability and the adequacy of safety and risk warnings (for a basic review, see Enghagen ${ }^{18}$ ). In all these cases, the warning, or information, needs to meet certain standards.

As a society, the USA has also endorsed the notion of a collective right to health relevant information through the formation of protection agencies like the Food and Drug Administration (FDA) and the Federal Trade Commission (FTC). Indeed, quality standards for information are part of the agencies' mandates. As part of its mission statement, the FDA takes responsibility for, "...helping the public get the accurate, science-based information they need to use medicines and foods to improve their health" ${ }^{19}{ }^{19}$ FC's general $^{\prime}$ rules against deception in advertising, as summarised by commissioner Varney, clarify how consumer rights to information include quality standards, specifically that businesses "must tell the truth and not mislead consumers...you can deceive a consumer by what you don't say as well as what you do say. If you omit information... that is material... then it is deceptive" ${ }^{20}$ (Note that the tobacco industry in the USA remains exempted from FDA regulation.) The US government is now required by law to ensure that information disseminated by its agencies meets standards that maximise the quality of information, including objectivity, utility, and integrity. ${ }^{21} 22$

Much of the health communication we discuss employs the internet, and ethical guidelines have been established specifically for the internet (as is discussed in the US Healthy People guidelines in health communication and health literacy). ${ }^{2}$ These guidelines are unambiguous on honesty: "Be truthful and not deceptive." They emphasise the importance of providing accurate and well supported information. There is no allowance for the use of deception in web based health communications. These standards reflect the rights of internet users, specifically, and individuals more generally, to expect to find quality information. Because the supply of internet information is essentially unregulated and potentially boundless, science based "data quality" is necessary to protect the credibility of legitimate channels of information. Deceptive messages will be contradicted in the multiply sourced "free press" internet leaving the credibility of all sources in question. In other words, even well intended deceptive messages present serious risks to the public health community.

\section{THE "NO SAFE CIGARETTE/TOBACCO PRODUCT MESSAGE" IS POOR QUALITY HEALTH INFORMATION}

The no safe cigarette message, currently a central theme of American tobacco control efforts, may have originated as a main finding of the 1981 Surgeon General's Report on "The changing cigarette" ${ }^{\prime 23}$ The first conclusion of this report was: "There is no safe cigarette and no safe level of consumption" (page vi). At the time this report was published, the emphasis on the "not safe" message may have been important to counteract the possible influence of the second conclusion that lower tar cigarettes were safer, according to the then available, now superseded, scientific evidence on lung cancer. ${ }^{24}$ In other words, the dominance of the "not safe" theme may have been important when the elaborated message said "but safer."

Messages or warnings on "no safe tobacco product" and "no safe cigarette" are now common from both tobacco industry and governmental health agency sources. ${ }^{23}$ 25-33 Consider the following, well promoted message from Philip Morris (PM): "...There is no "safe" cigarette...". ${ }^{25}$ The quotation is available on the PM website, and the emphasis on the "no safe cigarette" point was widely made in prime time television ads in 2003. ${ }^{26}$ Similarly, the US National Cancer Institute (NCI) website states: "There is no such thing as a safe cigarette". ${ }^{27} 28$ The US Centers for Disease Control's (CDC) Tobacco Information and Prevention Source web page informs: "WARNING: There is no safe tobacco product. The use of any tobacco product can cause cancer and other adverse health effects" ${ }^{\prime 3}{ }^{31}$ Though sources of health information that focus on the no safe tobacco/cigarette message often include additional information about particular tobacco use and smoking risks, the emphasis of the message is usually that no product is safe, instead of how safe or harmful any given product is. Considering the need for quality in health information, this emphasis presents at least two problems with messages that revolve around the not safe theme.

\section{Problem 1: it is not news}

In a world where no product is completely safe, it says little to warn that this or that product is "not safe". If all we knew about tobacco was it isn't "not safe", we likely would not need health agencies devoted to trying to control tobacco use. In addition, the large majority of the public have known explicitly for years that there is no safe tobacco product or cigarette. The Gallup poll has found that for the past three decades "the vast majority of Americans have recognised the harmful effects of smoking". ${ }^{34}$ They go on to note: "The most recent Gallup poll on smoking...shows that virtually all Americans-95\%-think cigarette smoking is harmful." As early as 1975, 95\% of high school seniors acknowledged at least some harm due to smoking ${ }^{35}$; by 1986, that percentage was $97 \%$. Yet recent work suggests that actual, specific knowledge of the health risks of smoking is poor. ${ }^{36}$ The 1986 Surgeon General's report on smokeless tobacco also found that among teenagers "over $85 \%$ thought that dipping and chewing tobacco can be harmful to health, but less than 55\% considered regular use to present moderate or severe risk" ${ }^{\prime 3}$ The very popularity of the no safe tobacco message, in its simplicity, promotes a limited view of tobacco; simply, it isn't safe and that is what one needs to know. Continuing to caution against tobacco use by emphasising the "not safe" message doesn't encourage the public to improve their understanding of tobacco risks. We think authorities would find it nearly useless to caution the public that "there is no safe automobile", and wonder why there appears to be so little scrutiny directed at the use of the no safe tobacco product message as a popular warning. 
Problem 2: what the message does not say

Today, telling consumers that there is "no safe cigarette" and "no safe tobacco product" does not tell them enough. When "nothing is safe", the degree of danger is crucial. The commercial success of modern low tar "safer" cigarettes ${ }^{38-40}$ indicates that: (1) consumers have a strong desire to know the relative or comparative risks of nicotine delivery systems, in this case, cigarettes; (2) risk beliefs influence product selection; and (3) the "no safe cigarette" message appears to have had little effect on the perception that low tar cigarettes are safer ${ }^{24}{ }^{41}$ Informing that nothing is safe simply does not prevent one from mistakenly believing that one "not safe" product is safer than another "not safe" product.

\section{PLAYING IT SAFE BY SAYING "NOT SAFE"}

Why is the "not safe" message so popular among so many sources? We suggest it is because the message itself is so safe and adaptable. For an agency like NCI, the message says, in effect, that they do not endorse the use of any kind of tobacco product. All scientific evidence supports the "not safe" message, while information on comparative risks necessarily involves a smaller science base. To offer a message on comparative risks of tobacco products is itself taking a kind of risk. Perhaps for some the "speech act" ${ }^{\prime 2}$ in saying "not safe" intends to convey: this product is "not safe enough to be recommendable for use" or as is written in one of the official US government required warning labels for smokeless tobacco products, "this product is not a safe alternative to cigarettes". ${ }^{43}$ Although this reasoning may help clarify the NCI use, the message still fails to convey whether or not a product is "safer" than another. This is a shortcoming of the not safe message as a risk communication tool, especially in the context of high consumer interest in "safer" products.

For the tobacco industry, the "not safe" message itself is also safe. The "not safe" message offers a simple truism and possibly a reminder that "nothing is safe" (so why worry particularly about tobacco?). If you've recently discussed smoking with someone who isn't interested in quitting, you may have been confronted with justifications like "we've all got to die from something" or "there's so much pollution in the air anyway, I might as well enjoy my smokes". When tobacco companies, especially industry leaders like PM, run television advertisements that there is no safe cigarette, they also avoid dealing with comparative risk statements. Though recent PM television ads caution that there is "no such thing as a safe cigarette" and "light and ultra-light cigarettes are no exception", their television advertisements do not caution that their most popular cigarettes are no safer than higher tar cigarettes and that smokers who have switched to these products have likely done nothing to reduce the health risks they incur by continuing to smoke. By using this particular message, already familiar from government health sources, PM avoids correcting any misperceptions smokers hold and creates the appearance of addressing their customers' health concerns by acknowledging the risks of smoking. What could be safer than to align completely with a dominant governmental message? Continuing to deny the health risks of cigarettes, in the face of overwhelming scientific data to the contrary, would likely do more damage to the industry's credibility than finding a "safe" way to agree with the data that smoking isn't safe. A task they accomplish by using the public health community's own message. ${ }^{44}$

The development of any industry credibility is regrettable because it has successfully marketed its products to the health conscious in part by failing to emphasise that light and low tar products are not safer than standard products. ${ }^{40}$ "Lights" and "ultra-lights" make powerful metaphorical claims of reduced risk which are not diminished by the "no safe cigarette" warning. ${ }^{41}$ Finally, the "not safe" or "not harmless" ${ }^{\prime 45}$ messages don't address the reality that some tobacco products are substantially safer than others. Smokeless tobacco (SLT), for example, while not safe, is substantially safer than cigarettes. ${ }^{76-53}$ Breaking with other government sources, the US National Institute on Aging (NIA) has agreed to change its health information on smokeless tobacco in response to a formal complaint about the following claim: "Some people think smokeless tobacco (chewing tobacco and snuff), pipes, and cigars are safer than cigarettes. They are not." The complaint charged that the NIA was not observing governmental standards on "data quality" by denying that smokeless tobacco was less dangerous that cigarettes and NIA has agreed to change this detail of the statement. $^{54}$

\section{ARE DECEPTIVE MESSAGES NECESSARY PUBLIC SAFEGUARDS AND ARE THEY JUSTIFIED TO PROTECT "SPECIAL" POPULATIONS?}

Some authorities believe that not informing, or even deceiving, some individuals is justified to protect the health of vulnerable groups, in particular nicotine addicts and youth. For example, two anonymous reviewers of an earlier draft of this paper specifically raised possible net public health losses as an argument in support of non-truthful messages on smokeless tobacco. The fear is that truthful comparative risk messages (saying that smokeless tobacco is dangerous, but is less dangerous than cigarettes) could: (1) prevent many smokers who planned to stop using tobacco from doing so; (2) recruit adolescents to smokeless use and subsequent smoking; or (3) substantially increases the numbers of tobacco users in society. ${ }^{55-58}$ From this perspective, trying to scare children away from smokeless tobacco by alleging that smokeless tobacco is equally or more dangerous than cigarettes is a constructive, even necessary, public health strategy. This perspective represents a classic utilitarian or consequentialist ethical position, where "ends" justify "means", when trying to achieve the greatest good for the greatest number of people. ${ }^{59}$

We, in contrast, are a kind of "rule utilitarian" and try to do the greatest good for the greatest number of people while also following certain rules-here, to be honest and nondeceptive. ${ }^{59}$ In practice it is usually very difficult to predict what will happen in the future, and we think it is a kind of ethical safeguard to limit the steps that will be taken to try to achieve the best for the most. In the case of smokeless tobacco, for example, although we think the concerns about net public health harm are more hypothetical than likely, even if the net ill-effects were likely, we disagree that deception in health information is an acceptable strategy. ${ }^{60-63}$

Tobacco addicts need to be treated as stakeholders in their own health. We grant that addiction can involve impaired judgment, particularly in decision making about the addictive substance, ${ }^{64-66}$ but we disagree that deceptive health information is a proper or in the long run even an effective tool for helping addicts. Experts on the risk in question (in this case, nicotine addiction) should try to convey that risk in a way that is meaningful to the public and that addresses the aspects of risk that are important to non-experts, the public. ${ }^{44}$ Transparency on the part of the experts, who are often government officials, is critical to how the public ( 1 ) receives the information, (2) understands it, and (3) trusts the source enough to follow the advice offered. Leiss and Powell describe a scenario in which an information vacuum develops as scientific evidence accumulates but is not conveyed to the public. ${ }^{44}$ When the vacuum is "discovered", the public seeks information from any source to fill the void. The perception that government agencies have failed to provide the information, or worse, have distorted it, can lead the public 
to doubt or disregard future governmental risk communication.

While we do not agree that deception in health information is a desirable, important, or ethical strategy for trying to reduce tobacco use, we do accept that public health policy could severely restrict, discourage, or ban certain products from sale..$^{7-8}$ Such regulations could also dictate how products may or may not be promoted or compared. However, enacting any policy that prioritises pubic health over individual rights obligates policymakers to provide transparent, non-deceptive justification for their actions. Public health ethics do provide for the suspension of individual rights (for example, quarantine in the case of severe acute respiratory syndrome (SARS) $),{ }^{67}$ but there is no deception involved. To be explicit, we agree that policy and regulatory decisions are complexly determined, but do not agree that deception with respect to basic facts is an ethically appropriate element of a science based policy. Scientific facts need to be reckoned with, not suppressed, by policymakers to uphold ethical obligations and to reduce the destructive impact of public perception of governmental risk "cover ups". ${ }^{44} 68$

Despite concerns about the unintended consequences of more detailed health messages, ultimately, the right to health relevant information is not contingent upon how an individual makes use of that information. The concern that the "safer" message will wrongly be interpreted as "safe" biases some toward saying "nothing is safe". Experts in product safety warnings remind us that, "even where the likelihood of warnings being effective may not be high, people have the right to be informed about safety problems confronting them"17 (pages 8-9). Although addiction may compromise the ability of addicts to make some choices, we do not support defining one's competence by his or her current smoking status. ${ }^{64-66}$ Though adolescents may struggle in particular with understanding and applying relative risk information to their behaviour, this difficulty does not justify misinformation or not informing at all. Creating messages for vulnerable audiences does not justify using deceptive, misleading, or incomplete information, instead it encourages health communicators to refine their methods in response to this challenge. For instance, messages geared toward adolescents could make use of emerging research on methods of promoting "numeracy" to simplify complicated information. ${ }^{69-71}$ Further, they could incorporate findings from the field of risk communication suggesting that information on the relative risk of death, which may be of little concern to teenagers, should be supplemented by information on other risks that are particularly salient to that audience (for example, bad breath). ${ }^{44}$

\section{RESPECTING THE RIGHT TO HEALTH RELEVANT INFORMATION}

Although harm reduction approaches to alleviating the burden of tobacco caused disease incorporate science based comparative risk information, the right to health information is a fundamental human right, distinct from harm reduction campaigns. The obligation to uphold this right to health information should not depend on whether or not public health officials deem harm reduction policies advisable. We encourage that the "utilitarians" of the tobacco control movement become "rule utilitarians" and treat certain strategies (for example, deception) as out-of-bounds. Tobacco control should promote science based knowledge and health literacy. The question of emphasis and content in tobacco risk communication is important and deserves attention. An urgent need for improving the quality of health information on tobacco is demonstrated by the troubling finding that a high percentage of tobacco control experts and advocates report that they would rather see a smoker switch

\section{What this paper adds}

In the USA, the message that there is "no safe cigarette" or "no safe tobacco product" has been widely promoted by both anti- and pro-tobacco groups. This theme has become dominant in many health communications on tobacco. Current health communications focusing primarily on the "no safe cigarette/tobacco" messages are so uninformative that they constitute a violation of the right to health relevant information on tobacco. Saying "not safe" does not inform about relative dangers (for example, "this cigarette is not even a little safer than that cigarette"); neither does it really provide the information sought by consumers who already know there is no safe tobacco product. The broad bases of a right to health relevant information are also reviewed, drawing examples from ethical and commercial traditions.

to lower tar cigarettes than smokeless tobacco (a recommendation inconsistent with the science base. $)^{72}$

Saying tobacco "isn't safe" isn't incorrect, but it isn't saying enough. Going beyond the no safe tobacco message to provide better information on the nature of risks from tobacco products and nicotine delivery systems is necessary to respect individual rights to health relevant information.

\section{Authors' affiliations}

L T Kozlowski, B Q Edwards, Department of Biobehavioral Health, The Pennsylvania State University, Pennsylvania, USA

Competing interests: none declared

\section{REFERENCES}

1 Harvard School of Public Health. Harvard School of Public Health: health literacy studies web site. http, www.hsph.harvard.edu/healthliteracy, (Accessed 4 March 2005).

2 Healthy People 2010 U.S. Healthy People guidelines in health communication and health literacy. http://www.ihealthcoalition.org/ethics/ ehealthcode0524.html (Accessed 4 March 2005)

3 Gilbert P. An annotated bibliography of health literacy and tobacco control/ prevention. Harvard School of Public Health: health literacy website, 2003. http://www.hsph.harvard.edu/healthliteracy/lit_tobacco.html.

4 US Department of Health and Human Services. Making health communication programs work: A planner's guide. Washington DC: NIH Office of Cancer Communications, 1989, (NIH Publication No. 89-1493).

5 US Department of Health and Human Services. Public Health Service. Healthy People 2000: national health promotion and disease prevention. Washington DC: US Department of Health and Human Services, 1990, (DHHS Publication No (PHS) 91-50213).

6 US Department of Health and Human Services. Healthy people 2010 objectives: draft for public comment. Washington DC: Public Health Service, 1998.

7 Kozlowski LT, O'Connor RJ. Apply federal research rules on deception to misleading health information: an example on smokeless tobacco and cigarettes. Public Health Reports 2003;118:187-92.

8 Kozlowski LT. Harm reduction, public health, and human rights: smokers have a right to be informed of significant harm reduction options. Nicotine Tob Res 2002; 4(suppl 2):S55-60.

9 United Nations. Universal Declaration of Human Rights. 1948. http:// www.un.org/Overview/rights.html (Accessed 24 February 2004).

10 Faden RR, Beauchamp TL. A history and theory of informed consent. New York: Oxford University Press, 1986.

11 Applebaum PS, Grisso T. Assessing patients' capacities to consent to treatment. N Engl J Med 1988;319:1635-8.

12 Applebaum PS, Grisso T. The MacArthur treatment competence study. I: mental illness and competence to consent to treatment. Law Hum Behav 1995; 19:149-74.

13 Coliver S, ed. The right to know: human rights and access to reproductive health information. Philadelphia: University of Pennsylvania Press, 1995.

14 Coliver S. The right to know: human rights and access to reproductive health information, Edited for Article 19. [London]: Article 19; Philadelphia, University of Pennsylvania Press, 1995.

15 Freedman LP. Reflections on emerging frameworks of health and human rights. In: Mann JM, Gruskin S, Grodin MA, Annas G, eds. Health and human rights. New York: Routledge, 1999:227-52.

16 Velasquez MG. Business ethics: concepts and cases. New Jersey: Upper Saddle River, 2002. 
17 Laughery KR, Hammond A. Overview. In: Wogalter MS, DeJoy DM, Laughery KR, eds. Warnings \& risk communication. London: Taylor \& Francis 1999:3-13

18 Enghagen LK. Fundamentals of product liability law for engineers. New York: Industrial Press, Inc, 1992.

19 Federal Trade Commission. Vision, mission, and goals, http://www.ftc.gov/ $\mathrm{ftc} /$ mission.htm (Accessed 4 March 2005).

20 Varney CA. To your health: An FTC review of safety related marketing. Prepared Remarks Before the 1996 International Consumer Product Health and Safety Organization Symposium. Orlando, Florida, 1996. http:// www.ftc.gov/speeches/varney/toyour.htm (Accessed 18 March 2004)

21 McKenna JW, Pechacek TF, Stroup DF. Health communication ethics and CDC quality control guidelines for information. Public Health Reports 2003;118:193-6.

22 Anon. Treasury and General Government Appropriation Act for the Fiscal Year 2001, Pub. L. No. 106-554, 515 Sect. December 21, 2000.

23 US Department of Health and Human Services. The health consequences of smoking: the changing cigarette. A report of the Surgeon General, 1981. Rockville, Maryland: Public Health Service, Office of the Assistant Secretary for Health, Office on Smoking and Health, 1981, (DHHS Publication No (PHS) 81-50156.).

24 National Cancer Institute. Risks associate with smoking cigarettes with low machine-measured yields of tar and nicotine, Smoking and Tobacco Control Monograph 13. Bethesda, Maryland: US Department of Health and Human Services, National Institutes of Health, National Cancer Institute (NIH Pub, No. 02-5074), October, 2001.

25 Philip Morris USA. Health issues: cigarette smoking and disease in smokers. http://www.pmusa.com/health_issues/cigarette_smoking_and_disease.asp (Accessed 24 February 2004).

26 Philip Morris USA. About Us: TV Advertisements. http://www. pmusa.com/ about_us/tvads/default.asp? source = instant_access (Accessed 24 February 2004).

27 National Cancer Institute. Cancer facts: the truth about "light" cigarettes. Reviewed 2003. http://cis.nci.nih.gov/fact/3_74.htm (Accessed 24 February 2004).

28 National Cancer Institute. Smokeless tobacco and cancer: questions and answers. Reviewed 2003. http://cis.nci.nih.gov/fact/3_63.htm (Accessed 18 March 2004)

29 Centers for Disease Control and Prevention. Tobacco Information and Prevention Source. Reviewed 24 January 2004. http://www.cdc.gov/ tobacco/ (Accessed 24 February 2004).

30 National Cancer Institute. Cancer Control and Population Sciences: Tobacco Control Research Smokeless Tobacco. Updated 1999. http:// cancercontrol.cancer.gov/tcrb/less_default.html (Accessed 24 February 2004).

31 Centers for Disease Control and Prevention. The Surgeon General's report for kids about smoking, Is smokeless tobacco safer than cigarettes? http:// www.cdc.gov/tobacco/sgr/sgr4kids/smokless.htm (Accessed 24 February 2004).

32 United States Department of Health and Human Services. Substance Abuse and Mental Health Services Administration National Clearinghouse for Drug and Alcohol Information. Tips for teens. Available at http://www.health.org/ govpubs/phd633/ (Accessed 24 February 2004).

33 American Cancer Society. Smokeless tobacco: highly addictive and no safer than smoking, 2004. http://www.cancer.org/docroot/PED/content/PED 10_2x_Smokeless_Tobacco_and_Cancerasp. (Accessed 24 February 2004).

34 Action on Smoking and Health. New gallup poll on smoking. http:// www.no-smoking.org/oct99/10-22-99-1.html (Accessed 24 February 2004).

35 US Department of Health and Human Services. Reducing the health consequences of smoking: 25 years of progress. A report of the Surgeon General, 1989. Rockville, Maryland: Public Health Service, Centers for Disease Control, Office on Smoking and Health, 1989, (DHHS Publication No (CDC) 89-8411.)

36 Weinstein ND, Marcus SE, Moser RP. Smokers' unrealistic optimism about their risk. Tobacco Control 2005; 14:55-9.

37 US Department of Health and Human Services. The health consequences of using smokeless tobacco: report of the advisory committee to the Surgeon General. Bethesda, Maryland: US Department of Health and Human Services, Public Health Service, 1986, (NIH Publication No. 86-2874). http:// profiles.nlm.nih.gov/NN/B/B/F/C/_/nnbbfc.pdf (Accessed 18 March 2004).

38 Shiffman S, Pillitteri JL, Burton SL, et al. Effect of health messages about "light" and "ultra light" cigarettes on beliefs and quitting intent. Tobacco Control 2001;10(suppl I):i24-32

39 Shiffman S, Burton SL, Pillitteri JL, et al. Test of "light" cigarette counteradvertising using a standard test of advertising effectiveness. Tobacco Control 2001; 10(suppl I):i33-40

40 Kozlowski LT, Goldberg ME, Yost BA, et al. Smokers' misperceptions of light and ultra-light cigarettes may keep them smoking. Am J Prev Med 1998;15:9-16.

41 Kozlowski LT. O'Connor RJ. Dealing with health fears: cigarette advertising in the United States in the twentieth century, In: Boyle P, Gray N, Henningfield J,
Seffrin J, Zatonski W, eds. Tobacco: science, policy, and public health. Oxford: Oxford University Press, 2004.

42 Searle JR. Speech acts: an essay in the philosophy of language, Cambridge University Press, 1969

43 Anon. United State Comprehensive Smokeless Tobacco Education Act of 1986 (15 U.S.C. §§ 4401-4408).

44 Liess W, Powell D. Mad cows and mother's milk: the perils of poor risk communication. McGill-Queens University Press, 2004

45 Centers for Disease Control and Prevention. Tobacco Information and Prevention Source : smokeless not harmless. http://www.cdc.gov/tobacco/ educational_materials/Smokeless_NOT_harmless.htm (Accessed 4 March 2005), (TIPS).

46 Rodu B, Cole P. Nicotine maintenance for inveterate smokers. Technology 1999;6:17-21.

47 Rodu B. An alternative approach to smoking control [editorial]. Am J Med Sci 1994:308:32-4.

48 Rodu B, Cole P. Smokeless tobacco use and cancer of the upper respiratory tract. Oral Surg Oral Med Oral Pathol Oral Radiol Endod 2002;93:51 1-5.

49 Critchley JA, Unal B. The health effects associated with smokeless tobacco use: a systematic review. Thorax 2003;58:435-43.

50 Warnakulasuriya S. Smokeless tobacco and oral cancer. Oral Diseases 2004; 10:1-4.

51 Huhtasaari F, Asplund K, Lundberg V, et al. Tobacco and myocardial infarction: is snuff less dangerous than cigarettes? BMJ 1992;305:1252-6.

52 Tobacco Advisory Group of the Royal College of Physicians. Nicotine addiction in Britain, 1999. http://www.rcplondon.ac.uk/pubs/books/ nicotine/ (Accessed 24 February 2004)

53 Foulds J, Ramstrom L, Burke M, et al. The effect of smokeless tobacco (Snus) on smoking and public health in Sweden. Tobacco Control 2003;12:349-59.

54 National Legal and Policy Center. National Institute on Aging forced to reexamine policy on smokeless tobacco products. PR Newswire, 14 July 2004. http://www.tobacco.org/news/170153.html (Accessed 4 March 2005).

55 McKenna JW, Pechacek TF, Stroup DF. Health communication ethics and CDC quality control guidelines for information. Public Health Reports 2003; 118:193-6

56 Leischow $\mathbf{S}$. Testimony before the committee on governmental reform United States House of Representatives. The science of reduced risk tobacco products. June 3, 2003. http://reform. house.gov/UploadedFiles/NIH\%20\%20Leischow\%20Testimony.pdf (Accessed 24 February 2004).

57 Hatsukami D. Testimony before the committee on governmental reform United States House of Representatives. Testimony on tobacco harm reduction. June 3, 2003. http://www.apa.org/ppo/issues/hatsukamitest603.html (Accessed 24 February 2004).

58 Henningfield J. Testimony before the committee on governmental reform United States House of Representatives. Reduced exposure/reduced risk tobacco products: an examination of the potential public health impact and regulatory challenges, June 3, 2003. http://www.apa.org/ppo/issues/ henningfield603.html (Accessed 24 February 2004).

59 Barnes G. Utilitarianisms. Ethics 1971:82:56-64

60 Kozlowski LT, Strasser AA, Giovino GA, et al. Applying the risk/use equilibrium: use medicinal nicotine now for harm reduction. Tobacco Control 2001;10:201-3.

61 O'Connor RJ, Kozlowski LT, Flaherty BP, et al. Most smokeless tobacco use does not cause cigarette smoking: results from the 2000 National Household Survey on Drug Abuse. Addictive Behaviors 2005;30:325-36.

$62 \mathrm{O}^{\prime}$ Connor RJ, Flaherty BP, Edwards BQ, et al. Regular smokeless tobacco use is not a reliable predictor of smoking onset when psychosocial predictors are included in the model. Nicotine Tob Res 2003;5:535-44.

63 Kozlowski LT, O'Connor RJ, Edwards BQ, et al. Most smokeless tobacco use is not a causal gateway to cigarettes: using order of product use to evaluate causation in a national U.S. sample. Addiction 2003;98:1077-85.

64 Charland LC. Cynthia's dilemma: consenting to heroin prescription. American Journal of Bioethics 2002;2:37-47.

65 Hall W, Carter L, Morley K. Heroin addiction and the capacity for consent: a reply to Charland. Addiction 2003;98:1775-6.

66 Satel SL, Goodwin FK. Is drug addiction a brain disease?. Washington DC Ethics and Public Policy Center, 1998.

67 World Health Organization. Communicable disease surveillance and response: severe acute respiratory syndrome (SARS). http://www.who.int/ csr/sars/en/ (Accessed 4 March 2005).

68 Ferreira C. Risk, transparency and cover up: media narratives and cultural resonance. Journal of Risk Research 2004;7:199-211.

69 Gigerenzer G. The psychology of good judgment: frequency formats and simple algorithms. Medical Decision Making 1996;16:273-80.

70 Schwartz LM, Woloshin S, Welch HG. Risk communication in clinical practice: putting cancer in context. J Ntl Cancer Inst Monograph No. 25, 124-33.

71 Woloshin S, Schwartz LM, Welch HG. Risk charts: putting cancer in context. J Ntl Cancer Inst. 2002;94: 799-804, incicancerspectrum. oupjournals. org/ cgi/content/full/jnci;94/11/799? ij. (Accessed 23 October 2004).

72 Warner KE, Martin EG. The US tobacco control community's view of the future of tobacco harm reduction. Tobacco Control 2003;12:383-90. 